\title{
Ego Depletion and the Humean Theory of Motivation
}

\author{
Patrick Fleming \\ James Madison University, Harrisonburg, USA \\ Email: fleminpj@jmu.edu
}

Received 24 June 2014; revised 26 July 2014; accepted 5 August 2014

Copyright (C) 2014 by author and Scientific Research Publishing Inc. This work is licensed under the Creative Commons Attribution International License (CC BY). http://creativecommons.org/licenses/by/4.0/

(c) (i) Open Access

\begin{abstract}
By what capacities do human beings engage in intentional action? Humeans about motivation claim that the source of all action is desire. Volitionalists claim that action has two distinct sources, one in the will and one in desire. Recent work suggests that volitionalism has some empirical support. Roy F. Baumeister and colleagues have argued for a phenomenon called "ego depletion". They argue that some aspect of the self exerts volition in a number of different contexts. The main evidence for this claim is that experimental subjects who engage in acts of self-regulation are less likely to engage in similar actions on later tests. The evidence calls for a reformulation of the Humean theory, not a rejection of it. And the reformulation is one that still has interest for metaethics. Many philosophers are interested in the Humean theory of motivation because they believe that it has implications for the correct theory of normative practical reasons. Here I argue that if the Humean theory of motivation was ever a threat to the objectivity of morality, it still is.
\end{abstract}

\section{Keywords}

Humean Theory of Motivation, The Will, Ego-Depletion, Objectivity of Morality

\section{Introduction}

By what capacities do human beings engage in intentional action? Humeans about motivation claim that the source of all action is desire. Volitionalists claim that action has two distinct sources. Action is often produced by desire, but it is sometimes the product of the will. Humeans protest that calm passions can adequately explain the actions some would like to attribute to the will. Because of this Humeans often paint volitionalists as committed to metaphysical excess that makes no predictions about experience. As Simon Blackburn puts it, believers in the will invoke a "Kantian Captain" to rule the passions that is "beyond empirical discovery" (Blackburn, 1998: p. 249). Empirically minded philosophers are likely to be skeptical of positing entities that make no dif- 
ference to the practice of science. Therefore, they tend to be Humeans.

Philosophers steeped in this traditional debate may find it surprising that a number of social psychologists claim to have uncovered evidence of the will. Roy F. Baumeister and colleagues have argued for a phenomenon called "ego depletion". They argue that some aspect of the self exerts volition in a number of different contexts. The main evidence for this claim is that experimental subjects who engage in acts of self-regulation are less likely to engage in similar actions on later tests. Subjects become ego depleted. They argue that this aspect of the self is distinct from desires because it becomes depleted even when the domains of action are very different. It is natural to identify this aspect of the self as the will. One might argue that if the Humean continues to deny the existence of the will it is he who is blinded by his metaphysical commitments.

In this paper I assess this challenge to the Humean theory of motivation. I believe the evidence calls for a reformulation of the Humean theory, not a rejection of it. And the reformulation is one that still has interest for metaethics. Many philosophers are interested in the Humean theory of motivation because they believe it has implications for the correct theory of normative practical reasons. That is, they believe that there is some important connection between what one can be motivated to do and what one ought to do. Furthermore, that connection might undermine the objectivity of morality. Of course, the nature of this connection and its implications is extremely controversial. Here I will put these issues to one side and argue that if the Humean theory of motivation was ever a threat to the objectivity of morality, it still is. This is because that while evidence for ego depletion is evidence for a source of motivation distinct from desire, it is not evidence for a will that can function to change the content of one's desires. To create a desire out of practical reason one still needs to start with desire in. Hence, there is no evidence that the will creates motivation with a distinctive normative content. In fact, a close examination of the evidence undermines some of the common sense support for volitionalism.

\section{The Humean Theory}

We need to get a bit clearer about what the Humean theory claims. Michael Smith is the most well known advocate of the Humean theory of motivation ${ }^{1}$. The key claim for Smith is that a desire is the only source of motivation. The evidence for this claim is that an explanation citing a belief/desire pair is applicable to all actions. Smith says it is the most basic kind of explanation because "all of the other explanations we commonsensically give presuppose this basic Humean story” (Smith, 2004: p. 157). Smith runs through a number of cases that have been presented as counterexamples to this claim and tries to show they all presuppose the Humean story. To take just one case, one might try to explain an action by some fact in the world. Something in the way of "she helped him because he needed help". Smith grants that this explanation may be true. However, this explanation requires that Humean one be true as well. If she did not believe he needed help and desired to help him, she could not have helped him because he needed it. If she was not aware of his need, then that could not be the reason she acted no matter what the other facts were. The same sort of dependence does not run the other way. The Humean explanation does not presuppose the fact-based explanation and may be correct where there are no such facts.

Note that the Humean does not deny that there are many good explanations of action that do not cite belief and desire pairs. Indeed, in most contexts to cite a belief and desire pair would be pointless because such explanations are so obvious. One would not even see an event as an action; much less asked why the agent did it, unless they already assumed the agent acted on the basis of a belief and desire. However, the obviousness of such explanations does not tell against their truth or their importance to the philosophy of action. The Humean can allow explanations citing the will as long as those explanations are understood to presuppose the more fundamental Humean story. At bottom, it is always desires that motivate ${ }^{2}$.

Smith claims the Humean explanation is what makes philosophy of action possible. It is true of every possible action and stands as a conceptual truth. Neil Sinhababu has presented a reformulation of the Humean theory that is one way logically weaker than Smith's and in one way stronger. Sinhababu's view is more modally modest in that he presents the theory as true of only human beings. There may be other possible agents with non-Humean psychologies. However, Sinhaabu's view is more metaphysically committed for the agents it is supposed to be true of. He breaks the theory down into two claims.

\footnotetext{
${ }^{1}$ See Smith (1987) and Smith (2004). My explication of his view focuses on Smith (2004).

${ }^{2}$ One might wonder why desires must play the key role since all explanations cite a belief/desire pair. Smith (1987) argues for this on the basis of each mental state's direction of fit. Beliefs represent the way the world is, while desires represent the way the agent would like the world to be. This argument has been much discussed and I will not add to it here. See Wallace (1990) for a response.
} 
The Desire-Belief Theory of Action [DBTA]: Desire is necessary for action, and no mental states other than desire and a mean-end belief are necessary for action.

Desire Out? Desire In [DODI]: Desires can be changed as the conclusion of reasoning only if a desire is among the premises of the reasoning (465: p. 2009).

While both have implications for metaethics, DODI seems to have more metaethical bite. We can see this because many critics of the Humean theory would attempt to accommodate DBTA. For instance, T.M. Scanlon claims that in broad sense of desire "anything that moves us (at least to intentional action) is likely to count as such a desire" (Scanlon, 1998: p. 37). So to ascribe an action to an agent also entails ascribing a desire to the agent. This seems to be accepting a version of DBTA. How can the non-Humean allow this? Following Nagel (1970), Wallace (1990) does so by making a distinct between motivated and unmotivated desires and claiming that pure reason can be practical in its issue. Unmotivated desires are desires that are simply given and do not depend on an evaluative belief or any rational principle. Motivated desires are those we adopt through deliberation. Wallace claims that some motivated desires are desires that can be explained in terms of the evaluative beliefs that they causally depend on. The Humean who accepts DODI tells us that practical reason can generate motivated desires, but only by invoking some unmotivated desire and means-end belief. That is, one can go from the desire for good pizza and the belief that Vito's serves good pizza to the motivated desire to go to Vito's. However, we cannot generate a new desire by citing beliefs alone. That is, one cannot go from the evaluative belief that it would be good to help those in need to the motivated desire to help Paul when he is need. One needs a desire to do good or a desire to help to generate the motivated desire to help Paul.

In denying DODI, the volitionalist allows for the possibility that practical reason can create novel normative content among our desires. In doing so he allows for possibility that caring about morality may be rationally required. This is why DODI has more metaethical bite than DBTA. The rejection of DODI allows one to defend the objectivity of morality, while accepting the DBTA. This is how I read Smith. He thinks certain principles of practical reason can generate new desires ${ }^{3}$. He claims that evaluative beliefs governs desires because believing one ought to $\phi$ is believing one would desire to $\phi$ if one were fully rational. A failure to comply with this belief constitutes psychological incoherence, which is the prototypical type of irrationality. So evaluative beliefs can generate motivated desires. Hence, what we can be motivated to do is not constrained by our given, unmotivated desires.

Now some might contend that Smith's version of objectivity is not robust enough. Nevertheless, denying DODI does give one more room to maneuver. If one accepts DODI, it gets much harder to defend the objectivity of morality. If DODI is true and there are some people who simply do care about morality, then there is no way to get them to care through reason. Of course, all of this is controversial and many philosophers would dispute the implications. The point is just that there are some good reasons to think DODI is the more important Humean thesis for metaethics. So my focus will be on DODI. I will argue that the empirical evidence undermines DBTA but not DODI. So if the Humean theory of motivation was ever a threat to the objectivity of morality, it still is.

The volitonalist I will engage with is Wallace. He argues that the will is necessary to make sense of certain aspects of rational agency. Wallace argues that those who reject a volitionalist conception of rational agency cannot "vindicate our conception of ourselves as self-determining agents, capable of complying with rational requirements even when we in fact violate them" (Wallace, 1999: p. 234). The claim seems to be that our common sense understanding of ourselves requires that we have a will. This requires accepting that "there is an important class of motivational states that are directly subject to our immediate control” (Wallace, 1999: p. 236). So Wallace claims that DODI is false because the will creates some of our motivational states. I will argue the empirical evidence does not support either of these views. A reformulated Humean thesis that rejects DBTA, but retains DODI is just as compatible with empirical evidence ${ }^{4}$.

Now let me offer a brief note about methodology. The Humean almost always presents the debate as about what is the best explanation of individual actions. That is, they consider a potential counterexample, say acting from a sense of duty, and argue that the Humean has a better explanation. As we will see this approach overlooks some psychological findings that a theory ought to account for to be empirically adequate. Sometimes what

\footnotetext{
${ }^{3}$ See Smith, 2004: pp. 17-42.

${ }^{4}$ It should be noted that Holton (2009) discusses some of the same empirical evidence to support a non-Humean theory. However, his work does not address DODI or the larger metaethical questions, so I will not address it here.
} 
needs explained in not an individual action, but some significant difference between agents for classes of actions. Paying attention to the psychological literature makes this clear. Volitionalists, on the other hand, often argue for their position on normative grounds or based on assumptions about our agency. They might claim we must deny the Humean theory to make sense of normativity or our sense of autonomy. This is clear in Wallace's remarks above. He appeals to our conception of ourselves and the practice of holding others responsible. We should note this sort of argument has no force on skeptics about morality or common sense assumptions about agency. Some Humeans, though Smith and Sinhababu are not among them, may happily accept these implications. The entire point of their critique may be to show that we cannot make sense of ourselves as self-determining agents or of the objectivity of morality. So to show we must believe in the will to believe in these features of agency gives them no reason to believe in the will. Hence, it would be dialectically better to appeal to factors that the Humean cannot so easily dismiss as irrelevant. As should be clear, the Humean cannot dismiss the findings of psychology, while maintaining his overall empiricist commitments.

\section{The Empirical Research}

Now let us turn the empirical research. In a series of studies Baumeister and colleagues present compelling evidence that suggests acts of volition spring from a single, limited resource. The general strategy of the research is to get subjects to engage in an act of self-regulation and then see how they fare in comparison to a control group on some further test that involves volition. Acts of volition include "making choices, overriding incipient responses, being active instead of passive, and replacing one response with another" (Schmeichel et al., 2003: p. 33). Researchers design experiments such that the tasks are very different in order to rule out the possibility that they are the products of some single motivation. They find that subjects become ego depleted. That is, subjects who self-regulate are consistently more likely to give up earlier on the second task. In one experiment subjects who had to resist the temptation to eat chocolate and instead eat radishes spent on average less than half as long working on puzzles than the control groups (Baumeister, Bratslavsky, Muraven, \& Tice, 1999). These findings have been replicated for a variety of forms of active choice or self-control and follow up tests on the ability to engage in volition. For instance, suppressing emotional responses to a film makes one more likely to quit squeezing a handgrip exerciser early (Muraven, Tice, \& Baumeister, 1998). The general conclusion reached by this research is that some limited resource, akin to strength or energy, is expanded in all acts of volition.

What will a Humean think of this research? They are likely to be unimpressed. They might counsel the psychologists to read 2.3.3 of the Treatise where Hume explains the mistake they are making. They are simply confusing a calm passion with operation of reason because both lack a qualitative dimension. Once we appreciate that all desires need not be violent cravings we will see that appeal to desires is still the best explanation. Before evaluating this explanation we should note a point made by Holton (2009). This response gets the phenomenology of such situations wrong. Hume was concerned to argue against the claim that reason can influence the will. He argued that simply because we feel no desires when contemplating action that does not show that they are not ultimately best explained by desires. However, in the cases discussed above the subjects likely do feel something. That is, when we resist temptation or persist in some unpleasant activity we have the sense that we are exerting effort. It is the sort of experience one is unlikely to confuse with the operation of reason or a calm passion. Rather, it is the experience of resisting a violent passion by means of something else quite like a violent passion. One has the sense of issuing motivational power to combat the violent passion.

The Humean needs to explain these results in terms of beliefs or desires that are plausibly ascribed to most people. We will consider possible desires first. An obvious candidate is that subjects have a desire to comply with the experimenter. Such a desire is plausibly attributed to subjects because of a general desire to be polite or comply with authorities. This desire explains the results because subjects would then participate in the experiment because of the desire, but at some point other desires will outweigh this desire. An interest in being polite will only go so far and at some point subjects will feel they have done enough. Ego-depleted subjects reach this state more quickly because they contributed more to the experiments in the initial tests. This Humean explanation is natural and plausible.

However, a further experiment included in Baumeister et al. (1999) is hard to reconcile with this account. In this study subjects were tested to see how long they would persist in watching a boring film. First, some subjects were put through an ego depletion task, while the control group was not ${ }^{5}$. Then subjects were told they were 
going to watch a boring film that they could quit at any time, but that they should watch enough of the film to answer some questions about it. Subjects were also divided into two quit conditions; active quit and passive quit. Those in the active quit had to press a button to stop the movie. Subjects in the passive quit were told to hold down the button until they were ready to stop. The experimenters hypothesized that ego depleted subjects would be less likely to engage in the active response because that involved volition in a way the passive option did not. These expectations were confirmed. Ego depleted subjects watched the film for a greater period of time when continuing was passive than when continuing was active. Non-depleted subjects did not have this effect. The researchers write that ego depleted subjects "are more prone to continue doing what is easiest, as if carried along by inertia" (1999: p. 331).

This data is hard for the Humean to account for. If the subjects just had a calm passion to comply with the experimenters, then the type of response should not matter. Depleted subjects should be more likely to quit early across the board. If there is any difference predicted by the Humean account, it would be in the opposite direction. Holding down a button is likely to be more physically demanding than pressing one, so a desire might be drained more quickly because of this. This is not what was found. Rather ego-depleted subjects watched the film for a longer period of time in the passive quit condition. What explains their greater persistence in the experiment? The difference seems to be the mental act of volition in deciding to actively quit. It seems that depleted subjects just continue to do what does not require volition regardless of the activity.

Not all is lost for the Humean. He might posit a desire on behalf of the agents regarding how willing they are to actively comply with the experimenters. This seems a rather strange desire to ascribe to large segments of the population. Regardless of this worry, Schmeichel, Vohs, and Baumeister (2003) found that ego depleted subjects performed poorly on intellectual tests that require active guidance by the self (questions pulled from the GRE), but found no effects for memorization skills or tests of common knowledge. It would seem that both are forms of actively complying with an experimenter. What seems to account for the difference is that subjects are engaged in acts of volition. The GRE question required that one thinks through the process. That depletes the ego. One becomes volitionally exhausted. The Humean can attempt to formulate other desire-based explanations, but one worries that this is motivated by metaphysical commitments and not a serious exploration of the empirical data.

Now let us consider whether the Humean can appeal in part to a belief to explain the results. One possible explanation is implicit in the work of Vohs and Schmeichel (2003). They argue that an experience of the extended now is the mechanism by which the ego is depleted. They hypothesized that self-regulation would lead to an elongated felt duration of time because self-regulating individuals pay more attention to time and each moment feels longer. In several studies they found that self-regulators overestimate the amount of time passed. Furthermore, they found a statistical correlation between perception of time passed and performance on future tests. They offer two reasons for thinking there is causal connection between subjective time experience and selfregulation. One reason is that people might have implicit or explicit limits regarding how much time they will spend on a task. Mistaken beliefs about how long they worked on the task might lead them to quit prematurely. Another reason is that individuals might feel "stuck" in time. If subjects are experiencing an extended now, then future goals might seem less important. Current desires might be given greater weight. An extended now that results in current desires taking on greater significance may make the non-fulfillment of those desires all the more distressing and distracting.

From this we can fairly easily cobble together a Humean explanation. Agents have a false belief about the passage of time from ego depletion. This might not only influence practical reason to create motivated desires to quit, but also might increase the force of current desires. It is this cognitive mistake that explains the difference. So there is no need to appeal to a distinct motivational source.

Upon reflection though, this explanation is not as plausible as it first seems. The claim is that people have some fairly specific belief about how much time they are willing to spend on the task. It needs to be fairly specific because they need a sense of when that limit has been reached. It is unlikely that individuals always or even usually have a limit of the amount of time they will spend on a task. For instance, did you have any implicit belief about how much time you would spend reading this paper? That seems unlikely. Moreover, attributing implicit beliefs to agents is always tricky business. More importantly, if we did place implicit time limits on all

\footnotetext{
${ }^{5}$ The control group was asked to read a page of text and cross out every instance of the letter "e”. The ego-depleted group was told to only cross out an "e" only if it was not next to another vowel or one extra letter away from one. Depleted subjects had to scan the text to find an "e" and resist the temptation to cross it out until they uncovered whether it meet the criteria.
} 
tasks, then self-regulation would be improved by simply informing individuals how long they actually spent. Once they saw their error they would continue on the task. That is extremely implausible. Now this is an empirical question. We could redesign all the ego depletion experiments by adding a condition in which we reminded ego depleted subjects exactly how much time has elapsed and see what changes occur. However, I know of no psychologist who has taken this issue up. I am skeptical though that all the impact of ego depletion would dissolve based on giving this information to the subjects. Something more complicated than a single false belief is going on here.

\section{The Implications of the Findings}

Sinhababu claims that, "to argue against the Humean theory, anti-Humeans should either find some data that it lacks the resources to explain or construct an alternative account that equals or exceeds it in simplicity" (Sinhababu, 2009: p. 486). The evidence of ego depletion is data that the Humean lacks the resources to explain. The evidence suggests that there is some general capacity to actively manage motivations, which is not plausibly explained by desire. Volitional responses seem to spring from some single capacity that can become depleted.

Does this refute the Humean theory? Well, it seems to seriously undermine DBTA. At the very least, it seems explanatory work can be done by the will. The Humean may reply that for every action we must ascribe a belief and a desire to the agent in order to understand as an action. That may be true, but the empirical evidence makes clear that explaining individual actions is not the only thing we need to explain. We also need to explain the patterns of behavior we see across different types of actions. And it seems appealing to any particular desire will not do that explanatory work.

Recall though that DODI is the more important Humean thesis. DODI is the claim that we can go only get motivated desires from unmotivated desires. To get desire out of practical reason we must start with desire in. Does the ego depletion evidence show that this is false? Does it show that we can generate motivated desires by an act of the will? The evidence does not show this. The evidence only shows that acts of self-regulation tend to lessen one's capacity for future volitional acts. That is, we have the capacity to restrain our desires and not let them run their usual course. Does this vindicate Wallace's claim that "there is an important class of motivational states that are directly subject to our immediate control" (Wallace, 1999: p. 236)? The evidence suggests that constraining desires are directly subject to our immediate control. However, there is no evidence that the content of our desires is directly subject to our immediate control. There is no evidence that we create new desires through an act of the will. The volitionalist needs that to undermine DODI thesis.

Now one might respond that the volitionalist still has the best of the dispute. The Humean has been forced to give ground and volitionalist has found some support for their position besides common sense and normative practice. One might reasonably claim that we cannot expect psychological findings to directly refute a philosophical theory. All one could hope is that one theory is better supported by the relevant empirical findings. One could claim that the ego depletion evidence does just that. Nevertheless, I think reflection on the data also undermines some of the intuitive appeal of a volitionalist's account. Wallace claims that we directly control some of our motivations. This does seem to capture our own sense of agency. However, the evidence of ego depletion might explain how we mistake one capacity for another. Exercises of self-control involve of using the will to control more natural responses. This is likely the source of our idea of having immediate control over of some of our motivational states. We have the experience of holding back a desire. This might be easily confused with the experience of creating a desire. However resisting or managing an urge is not the same thing as fundamentally changing what one cares about. The evidence of ego depletion is evidence of constraining desires, not evidence a distinct source of motivational content. Since both are active motivational management, it might be easy to mistake one for the other.

Of course, that does not mean that volitionalists are making that mistake. But it does mean we ought to be skeptical to appeals to our conception agency because common sense may make this error. To assess whether we ought to accept DODI thesis we would need to examine volitionalists' accounts of how we create motivation. We cannot do that here. But there is no direct refutation of DODI from current psychological evidence.

\section{References}

Baumeister, R. F., Bratslavsky, E., Muraven, M., \& Tice, D. M. (1999). Ego Depletion: Is the Self a Limited Resource? The Self in Social Psychology (pp. 317-336). Ann Arbor, MI: Psychology Press. 
Blackburn, S. (1998). Ruling Passions. Oxford: Claredon Press.

Holton, R. (2009). Willing, Wanting, Waiting. Oxford: Oxford University Press. http://dx.doi.org/10.1093/acprof:oso/9780199214570.001.0001

Muraven, M., Tice, D. M., \& Baumeister, R. F. (1998). Self-Control as Limited Resource: Regulatory Depletion Patterns. Journal of Personality and Social Psychology, 74, 774-789. http://dx.doi.org/10.1037/0022-3514.74.3.774

Nagel, T. (1970). The Possibility of Altruism. Oxford: Claredon Press.

Scanlon, T. M. (1998). What We Owe to Each Other. Cambridge, MA: Harvard UP.

Sinhababu, N. (2009). The Humean Theory of Motivation Reformualted and Defended. Philosophical Review, 118, $465-500$. http://dx.doi.org/10.1215/00318108-2009-015

Smith, M. (1987). The Humean Theory of Motivation. Mind, 96, 36-61. http://dx.doi.org/10.1093/mind/XCVI.381.36

Smith, M. (2004). Ethics and the A Priori. Cambridge: Cambridge University Press. http://dx.doi.org/10.1017/CBO9780511606977

Vohs, K. D., \& Schmeichel, B. J. (2003). Self-Regulation and the Extended Now: Controlling the Self Alters the Subjective Experience of Time. Journal of Personality and Social Psychology, 85, 217-230. http://dx.doi.org/10.1037/0022-3514.85.2.217

Wallace, R. J. (1990). How to Argue about Practical Reason. Mind, 99, 267-297.

Wallace, R. J. (1999). Three Conceptions of Rational Agency. Ethical Theory and Moral Practice, 2, 217-242. http://dx.doi.org/10.1023/A:1009946911117 
Scientific Research Publishing (SCIRP) is one of the largest Open Access journal publishers. It is currently publishing more than 200 open access, online, peer-reviewed journals covering a wide range of academic disciplines. SCIRP serves the worldwide academic communities and contributes to the progress and application of science with its publication.

Other selected journals from SCIRP are listed as below. Submit your manuscript to us via either submit@scirp.org or Online Submission Portal.
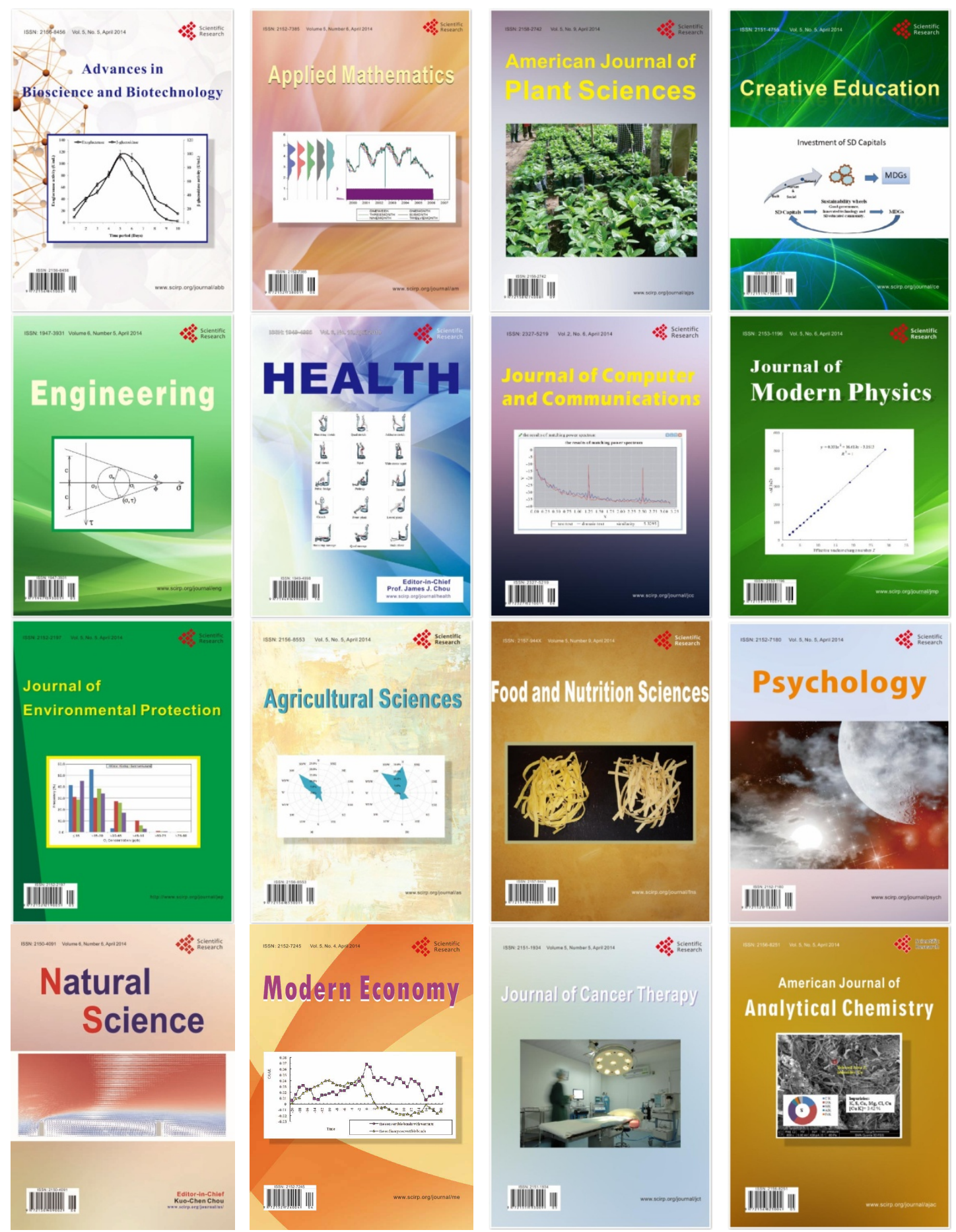